\title{
Nasionalisme di Puncak Gunung: \\ Etnografi Komunitas Pemuda Pecinta Alam dalam Wacana Ecosophy dan Gerakan Lingkungan di Malang
}

Fuji Riang Prastowo, A. Harun Al Rasyid

Universitas Gadjah Mada | Universitas Brawijaya

fujiriangprastowo@ugm.ac.id | achmadharun1998@gmail.com

\section{ABSTRACT}

The Nature Lovers community, in Indonesia, have a unique habit of celebrating the conquest of the mountain peak by singing a National anthem of Indonesia Raya along with the raising of nation flag. Interestingly, many of them have a dream to attend a flag-raising ceremony in order to celebrate the independence day of the Republic of Indonesia on 17 August at the top of the mountain. By using the 'phenomenology-based ethnography' method among the Nature Lovers community in Malang, this study seeks to answer about how these young people construct a discourse on environmental movements in their climbing activities and how they construct nationalism through their climbing rites. Analysis of the study used the concepts of Ecosophy from Arne Naess and Nationalism from Benedict Anderson. Through these two conceptual frames, the results of the study show that there is a close connection between mountain climbing and ecosophy discourse with nationalism, both of which have similar philosophical values in search of the self through natures. Climbing is the effort of young people to get closer to nature and the process of finding themselves through the conquest of the ego during the journey to further strengthen the value of ecosophy or individual connection to nature. While patriotic celebrations at the top of the mountain are manifestations of nationalism rooted in the 'deep ecology movement' which is constructed by the 'imagined community' based on the solidarity of the climbers who have the same souls in nature. It can be said that the connection between ecosophy and nationalism is represented by the romanticism of the mountain climbing.

KEYWORDS Nature Lovers | Hiking | Ecosophy | Nationalism

\section{PENDAHULUAN}

Salah satu fenomena menarik di kalangan anak muda adalah menjamurnya komunitas-komunitas pendaki gunung. Dalam konteks ini, pendakian gunung bukan hanya soal seni 'menaklukan' medan yang curam demi mencapai puncak gunung, lalu kemudian selfie agar diketahui khalayak banyak lewat media sosial. Lebih dari itu, tak sedikit anak muda yang memaknai pendakian gunung sebagai 'jalan hidupnya untuk memaknai lebih dalam tentang kehidupan, atau hanya sekadar mengenal dirinya sendiri'. Menurut MacCannel (1999) ke- giatan pendakian adalah upaya penaklukan diri sendiri dari kalangan leisure class untuk menikmati hidup dengan cara mendekat kepada alam.

Walaupun sampai dengan sekarang, pendakian gunung seringkali memakan korban jiwa. Namun, tidak menurunkan hasrat para pemuda untuk menaklukan puncak-puncak gunung. Uniknya, ketika menjelang 17 Agustus, hari kemerdekaan Republik Indonesia, sudah dapat dipastikan puncak-puncak gunung di Indonesia terutama di Puncak Mahameru akan dipadati oleh para pendaki gunung untuk 
melakukan upacara bendera (Arifin 2018; Hartik 2018; Yustiana 2018). Walaupun pihak taman nasional telah melarang keras upacara HUT kemerdekaan RI di Puncak Semeru karena keselamatan, tetap saja banyak pendaki yang ingin melakukan upacara bendera di Puncak tertinggi di Pulau Jawa tersebut, secara diam-diam.

"Kalau Upacara di Ranukumbolo, batas pendakian sampai Kalimati, kadang masih banyak yang nekat di Mahameru, itu kita larang keras" ujar Kepala TNBTS John Kennedie (Dikutip detiktravel, Yustiana 2018).

Dalam studi tentang pendakian sendiri erat kaitannya dengan narasi patriotisme dan nasionalisme sebagai wujud 'secular pilgrimage atau ziarah sekuler (MacCannell 1999) dalam mengonstruksikan identitas suatu bangsa atau 'civil religion' (Forbes 2017), yang merupakan perwujudan dari pilgrimage to the motherland (Katriel 1995). Kreiner dan Kliot (2017 menyatakan bahwa dari sejumlah pendaki yang melakukan tiyul (pendakian dalam bahasa Hebrew), pendakian secara periodik ke Israel National Trail dapat diasosiasikan sebagai wujud dari place attachment, sense of place, dan state and nation building dalam kerangka membangun bersama-sama Israeli Nationhood (rasa sebangsa) dengan wadah budaya dan sejarah. Dengan kata lain, kegiatan pendakian yang dilakukan merupakan upaya para pendaki dalam mengonstruksikan ikatan emosional dan afiliasi kepada negara sebagai ikatan manusia terhadap tempat.

Senada dengan argumen di atas, Ween dan Simone (2012) secara lugas menyatakan bahwa kegiatan pendakian adalah upaya mengkonstruksi rasa cinta tanah air kepada lanskap alam Norwegia yang dilindungi oleh negara. Dalam penelitiannya pada asosiasi Den Norske Turistforening (DNT, the Norwegian Trekking Association), pendakian bukan hanya dimaknai sebagai kegiatan pendakian semata tetapi juga praktik filosofis hubungan manusia kepada alamnya atau yang sering dikatakan dengan ecosophy atau deep ecology movement karena mempertimbangkan faktor 'kedalaman jiwa' dalam membangun sebuah identitas. Berdasarkan rasa cinta tanah air yang dikonstruksikan secara komunal ini lantas dapat membentuk identitas sebangsa sebagai orang Norwegia yang notabene memang terlekat sebagai environmentalism. Alam dan Norwegia adalah satu kesatuan yang tidak dapat dipisahkan, begitu pula dengan pendakian.

Di Indonesia, dari banyaknya komunitas pendaki gunung, salah satu yang paling terkenal adalah "Pecinta Alam" yang biasanya terafiliasi dengan lembaga pendidikan baik di tingkat Perguruan Tinggi hingga sekolah menengah. Sehingga komunitas-komunitas tersebut banyak didominasi oleh pemuda yang mengklaim dirinya sebagai komunitas yang mecintai alam. Lalu yang menarik untuk dikaji lebih mendalam dalam sudut padang ilmu sosial adalah tentang bagaimana relevansinya pendakian gunung dengan kegiatan yang dianggap sebagai tindakan 'mencintai' alam yang selaras dengan domain gerakan lingkungan lainnya.

Singkat kata, berdasarkan narasi cerita di atas yang didukung lewat studi-studi terdahulu berkaitan dengan nasonalisme dan lingkungan, tulisan ini berusaha mengangkat cerita-cerita para pemuda yang tergabung dalam komunitas pemuda "Pecinta Alam" melalui studi etnografi. Wilayah studi dilakukan di Kota Malang dengan dua alasan utama. Pertama, Malang merupakan 'rumah' bagi gunung tertinggi di Pulau Jawa yakni Mahameru dan gunung populer lainnya yang menyebabkan tidak pernah sepi dari para pendaki, sehingga Malang menjadi melting-pot dari seluruh komunitas Pecinta Alam di Indonesia. Kedua, Malang yang merupakan salah satu kota pelajar di Jawa dengan banyaknya perguruan tinggi merupakan rahim munculnya embrio-embrio komunitas pecinta alam di Malang. Studi ini lantas berusaha menjawab rumusan utama melalui studi etnografi: Bagaimana konstruksi nasionalisme terbangun dalam gerakan lingkungan berbasis ecosophy di kalangan komunitas pemuda pecinta alam di Malang? 


\section{METODE PENELITIAN}

Penelitian ini menggunakan pendekatan fenomenologis yang digunakan untuk memotret pemahaman subjektif dari setiap informan dalam rangka mendefinisikan makna dari pengalaman sehari-hari mereka (Wojnar dan Swanson 2007; Finlay 1999). Secara lebih spesifik, studi ini menggunakan metode "phenomenology-based ethnography”. Menurut Lehn dan Hitzler (2015) adalah sebuah metode etnografi yang menempatkan pandangan subjektif informan sebagai basis utama pondasi refleksi empirisnya, bukan dari pengalaman peneliti seperti metode etnografi klasik. Dengan kata lain, analisis yang digunakan berdasarkan cerita-cerita dari pandangan subjektif dan pengalaman informan serta meminimalisir perspektif peneliti dalam membangun narasi empiris.

Dalam studi ini, penelitian lapangan dilakukan pada rentang bulan Februari-Juli 2019 di Malang dengan mengikuti aktivitas komunitas pemuda Pecinta Alam serta melakukan wawancara mendalam dan small talks selama pendakian bersama atau via media sosial. Wawancara dilakukan pada 13 individu yang merupakan anggota komunitas pemuda Pecinta Alam atau mereka yang hobi mendaki gunung. Data-data yang didapatkan dari penelitian yang dilakukan lewat offline atau online lantas diolah dengan sejumlah teknik seperti transkripsi, indexing, dan coding. Sebagai catatan, kedua peneliti sendiri memiliki hobi traveling serta mendaki gunung, sehingga metode 'phenomenology-based ethnography' lebih tepat digunakan dalam studi ini untuk mengurangi bias dalam narasi pendakian di kalangan pemuda Malang. Narasi-narasi yang dibangun berdasarkan reflektif bersama sebagai orang yang sama-sama 'mencintai alam". Seluruh nama informan yang digunakan dalam tulisan adalah nama sapaan asli setelah mendapatkan izin penggunaannya oleh para informan yang beranggapan tulisan ini bukan sesuatu yang sensitif, sehingga mereka sangat terbuka dalam penelitian ini.

\section{KERANGKA TEORI}

Kajian pendakian ini masuk dalam rumpun leisure studies dengan penyebutan konsep pendakian dalam bahasa Inggris sebagai 'hiking, trail walking, trekking, dan mountain climbing' (Kay dan Moxam 1996). Seperti yang telah dijelaskan di atas, bahwa studi-studi terdahulu membuktikan ada korelasi yang kuat antara praktik pendakian sebagai secular pilgrimage (MacCannel 1999), dengan upaya kontruksi nasionalisme atau patriotisme sebagai suatu bangsa (Kreiner dan Kliot 2017). Selain itu, kegiatan pendakian dapat dikatakan sebagai upaya para pendaki mengontruksikan identitas sebagai suatu bangsa (Forbes 2017; Katriel 1995), dalam kerangka deep ecology movement berdasarkan filosofi bahwa manusia dan alam memiliki ikatan yang kuat (Ween dan Simone 2012).

Dari dua penelitian yang dilakukan di Israel (Kreiner dan Kliot 2017) dan di Norwegia (Ween dan Simone 2012), kegiatan pendakian yang dilakukan di Indonesia oleh para komunitas pemuda Pecinta Lingkungan dapat dikatakan memiliki karakteristik serupa yakni adanya upaya para pemuda ini mewacanakan patriotisme dan nasionalisme pada kegiatan pendakian yang didefinisikan sebagai gerakan lingkungan. Oleh karena itu, sebagai basis analisis, dua teori akan digunakan sebagai kerangka tulisan ini yakni Ecosophy dari Arne Naess dan Nasionalisme dari Benedict Anderson.

Ecosophy: Arne Naess

Arne Naess (1989) dalam bukunya berjudul "Ecology, Community and Lifestyle: Outline of an Ecosophy', mendefinisikan ecosophy sebagai personal system atau pandangan filosofis seseorang tentang lingkungan dan bagaimana prinsip-prinsip tentang lingkungan diresapi dalam hati individu tersebut melalui implementasi tindakan individu atau menginisiasi gerakan lingkungan. Naess menyampaikan bahwa ecosophy sebagai pandangan filosofis seseorang tentang lingkungan memang tepat 
jika dipotret dengan pendekatan fenomenologis. Ecosophy sendiri secara epistemologis merupakan gabungan dari dua kata yakni 'oikos' dan 'sophia' yang bermakna tatanan dan wisdom (kebijaksanaan), sedangkan eco berasal dari ecology yang bermakna luas tidak hanya tentang lingkungan dalam arti ekologis alam tetapi juga ekologis sosial seperti di lingkungan keluarga atau komunitas. Ecosophy sering disejajarkan dengan ecophilosophy walaupun keduanya sebenarnya berbeda konteks. Ecophilosophy yang notabene gabungan dari dua kata yakni ecology dan philosophy, adalah area studi atau ilmu tentang filsafat lingkungan, sedangkan ecosophy adalah nilai-nilai filosofis tentang lingkungan yang dipahami dan diterapkan oleh seseorang.

"We study ecophilosophy, but to approach practical situations involving ourselves, we aim to develop our own ecosophies" (Naess 1989).

Sehingga dapat ditarik kesimpulan bahwa ecosophy menurut Naess adalah "a philosophical world-view or system inspired by the conditions of life in the ecosphere" yang diimplementasikan melalui beberapa moda. Pertama, melalui ‘self-realisation' yang adalah upaya individu untuk tidak menjadi manusia egois atau self-centred tetapi memiliki kesadaran penuh bahwa ia bagian dari ekologi alam semesta yang berisi beragam flora dan fauna, sedangkan manusia hanyalah bagian terkecil dalam alam tersebut. Secara filosofis, Naess mengatakan bahwa self-realisation berasal dari kata dalam bahasa Norwegia yakni Selv-realisering yang memiliki makna semantik sebagai 'active condition'. Kedua, identification yang dapat diartikan sebagai identifikasi atau mengenali diri sendiri sebagai manusia dalam sistem ekologi yang utuh di mana manusia tidak bisa berdiri sendiri dengan keegoisannya. Dalam hal ini, Naess lebih detail mengatakan bahwa identifikasi yang ia maksud merupakan the sense of the widest interpretation of love in nature'. Ketiga, nilai intrinsik atau dalam bahasa Norwegia disebut dengan naturens egenverdi yakni nilai-nilai instrinsik seseorang yang membedakan individu satu dengan individu lainnya tentang bagaimana koneksi diri kepada alam (the connections to the Self of nature).

Ketiga moda di atas lantas dikaitkan Naess pada apa yang disebut dengan 'deep ecology movement' yakni sebuah gerakan lingkungan yang lebih menekankan pada kedalaman atau filosofis tentang lingkungan daripada masifnya suatu gerakan. Dalam hal ini, deep ecology lebih menekankan pada kualitas suatu gerakan dibandingkan kuantitas gerakan yang terkesan lebih banal atau dangkal. Pola gerakannya tergolong menggunakan counter-culture yang bisa bermodel advokasi dengan radikal atau konservatif dalam skala individu atau kelompok. Titik tekanannya adalah pada penerapan ecosophy sebagai akar gerakan yang berarti akar gerakan adalah nilai-nilai filosofis tentang alam.

Nasionalisme: Benedict Anderson

Dalam dimensi antropologis, secara individu, nasionalisme dapat dimaknai sebagai suatu sistem nilai yang berisi tentang kesetiaan seseorang yang termanifestasi lewat perasaan dan tindakannya kepada bangsa dan negara yang dilandasi oleh rasa memiliki. Benedict Anderson (1983) mengatakan bahwa suatu bangsa (nation) adalah suatu komunitas yang terangkai dalam bingkai politik dengan suatu kedaulatan yang diimajinasikan, sehingga dapat pula disebut sebagai imagined community. Bangsa tersebut disatukan oleh kepemilikan abstrak yang digambarkan sebagai sesuatu yang sama persis dirasakan oleh semua anggota komunitasnya. Komitmen inilah yang kemudian membentuk suatu nation state atau negara kebangsaan sehingga anggotanya rela mengorbankan segenap jiwanya untuk membela komunitasnya atau oleh Ernest Renan disebut bahwa unsur utama terbentuknya suatu bangsa lewat hasrat bersama untuk bersatu padu. Dengan kata lain, nasionalisme adalah suatu ideologi yang teranalogi dirasakan serupa oleh individu dalam ikatan bangsa dan negara. 
Lebih lanjut, nasionalisme akan memunculkan identitas politik yang dikonstruksikan secara bersama-sama oleh suatu bangsa yang kemudian diterjemahkan dengan simbol kewarganegaraan. Jiwa-jiwa patriotik menjadi gambaran ideal konsep nasionalisme yang oleh bangsa Indonesia dimaknai sebagai 'tanah air' yang merupakan harga mati yang harus dipertahankan jiwa dan raga. Dalam konteks studi ini, nasionalisme tercermin dari lahirnya simbol-simbol yang dilestarikan oleh seluruh bangsa Indonesia dengan simbol bendera merah putih serta ritus upacara bendera yang dilakukan setiap tanggal 17 Agustus.

\section{Profil Pecinta Alam di Malang}

Seperti halnya Yogyakarta yang dikenal sebagai kota pendidikan, Malang juga memiliki predikat sebagai salah satu kota pendidikan yang favorit di Indonesia. Hal ini didukung dengan adanya kurang lebih 60 perguruan tinggi yang berlokasi di kota ini. Banyaknya perguruan tinggi juga menjadi cikal bakal meningkatnya organisasi eksternal maupun internal mahasiswa, salah satunya organisasi pecinta alam. Setidaknya hingga tahun 2019 ada 13 komunitas pendaki gunung yang digawangi oleh pemuda-pemuda yang didominasi oleh afiliasi dunia kampus seperti:

ANALISIS DAN PEMBAHASAN

\begin{tabular}{|l|l|l|}
\hline No. & Profil Pecinta Alam di Malang & \multicolumn{1}{|c|}{ Keterangan } \\
\hline 1. & Impala UB & $\begin{array}{l}\text { Dibentuk pada awal Juni 1975. Kegiatan Impala UB dalam bidang } \\
\text { Lingkungan, Olahraga, Sosial Ilmiah, Pemberdayaan masyarakat. }\end{array}$ \\
\hline 2. & Dimpa UMM & $\begin{array}{l}\text { DIMPA berdiri berdasarkan pada orang-orang yang mempunyai } \\
\text { kepentingan sama, yaitu petualang-petualang yang mencinta } \\
\text { alam. Dibentuk pada 17 oktober tahun 1983. Sejauh informasi } \\
\text { yang diperoleh, DIMPA UMM bergerak dibidang olahraga dan } \\
\text { lingkungan terlihat dalam website dan sosial media Instagram- } \\
\text { nya. }\end{array}$ \\
\hline 3. & Impala UNMER Malang & $\begin{array}{l}\text { MAPALA Unmer didirikan pada tanggal 17 April 1984 berdasar- } \\
\text { kan Surat Keputusan Rektor nomor: Skep / 23 / UM / IV / 1984 } \\
\text { tentang Organisasi Ikatan Mahasiswa Pecinta Alam (IMAPALA) } \\
\text { Universitas Merdeka Malang. Secara garis besar Imapala UN- } \\
\text { MER bergerak di bidang organisatoris dan olahrga, dan gerakan } \\
\text { lingkungan lainnya. }\end{array}$ \\
\hline 4. & Himakpa ITN Malang & $\begin{array}{l}\text { Himakpa ITN malang didirikan pada tahun 1978. Himakpa ITN } \\
\text { malang awalnya bergerak sebagian besar dalam bidang penda- } \\
\text { kian atau ekspedisi gunung-gunung di Indonesia, namun seiir- } \\
\text { ing berjalannya waktu HIMAKPA saat ini membagi beberapa } \\
\text { pergerakan mereka dalam bidang olahraga arus deras dan arus } \\
\text { lemah, maksud dari itu agar memperluas gerak mereka dalam hal } \\
\text { ekspedisi hingga menjalin relasi mancanegara. }\end{array}$ \\
\hline 5. & $\begin{array}{l}\text { Mapawika UNIKATOLIK } \\
\text { WIDYA KARYA } \\
\text { Mapawika Widya Karya aktif di bidang pendakian dan gerakan } \\
\text { lingkungan lainnya. }\end{array}$ \\
\hline
\end{tabular}




\begin{tabular}{|c|c|c|}
\hline 6. & $\begin{array}{l}\text { Ukmpa WANAPALA UNI- } \\
\text { TRI }\end{array}$ & $\begin{array}{l}\text { Dibentuk pada } 05 \text { November } 2001 \text { di Gunung Panderman. Ukm- } \\
\text { pa banyak mengkampanyekan perihal sampah, dan lingkungan, } \\
\text { apalagi akhir-akhir ini permasalahan yang sedang marak terjadi } \\
\text { tentang sampah plastik, hingga menjual beberapa produk seperti } \\
\text { tottebag tentang pentingnya plastic. }\end{array}$ \\
\hline 7. & $\begin{array}{l}\text { HimpasVignecvara } \\
\text { SEKOLAH TINGGI } \\
\text { ILMU EKONOMI MA- } \\
\text { LANGKUCECWARA }\end{array}$ & $\begin{array}{l}\text { Dibentuk pada } 18 \text { November } 1980 \text { aktif dalam kegiatan pendaki- } \\
\text { an gunung dan gerakan lingkungan lainnya. }\end{array}$ \\
\hline 8. & $\begin{array}{l}\text { Mapala Tursina UIN MALI- } \\
\text { KI MALANG }\end{array}$ & $\begin{array}{l}\text { Mapala ini dibentuk pada } 20 \text { desember } 1995 \text { dan bergerak pada } \\
\text { bidang olahraga, pendakian maupun gerakan lingkungan lainn- } \\
\text { ya. }\end{array}$ \\
\hline 9. & $\begin{array}{l}\text { Kamapalabunglon IKIP } \\
\text { BUDIUTOMO MALANG }\end{array}$ & $\begin{array}{l}\text { Awalnya pada tahun } 2003 \text { Kamapalabunglon berdiri lalu sempat } \\
\text { tidak aktif hingga } 2007 \text {. Kamapalabunglon bergerak pada bidang } \\
\text { pendakian dan gerakan lingkungan lainnya. }\end{array}$ \\
\hline 10. & $\begin{array}{l}\text { Kapa85 UNIVERSITAS GA- } \\
\text { JAYANA MALANG }\end{array}$ & $\begin{array}{l}\text { Sebuah Organisasi Pecinta Alam yang didirikan pada tanggal } 30 \\
\text { Maret } 1985 \text { di Pucak Gunung Panderman Batu Malang oleh se- } \\
\text { kelompok mahasiswa Universitas Gajayana Malang, bergerak di } \\
\text { bidang pengabdian, olahraga yakni arus berat dan arus ringan, } \\
\text { pendakian dan gerakan lingkungan lainnya. }\end{array}$ \\
\hline 11. & $\begin{array}{l}\text { Kepakelang STIKI } \\
\text { MALANG }\end{array}$ & $\begin{array}{l}\text { Tidak diketahui berdirinya lewat penelusuran data sekunder. } \\
\text { Pecinta Alam ini bergerak di bidang olahraga, pendakian dan } \\
\text { gerakan lingkungan lainnya. }\end{array}$ \\
\hline 12. & $\begin{array}{l}\text { Kmpa Ranti Pager Aji UNIS- } \\
\text { MA }\end{array}$ & $\begin{array}{l}\text { Berdiri secara resmi Pada tanggal } 10 \text { Desember } 1989 \text { sebagai } \\
\text { satu -satunya unit kreatifitas mahasiswa ( UKM ) Pecinta alam } \\
\text { yang bernaung dibawah Universitas Islam Malang. KMPA "RPA" } \\
\text { mempunyai orientasi kegiatan dalam bidang Olah raga, Sosial, } \\
\text { Ilmiah, dan Rekreasi. }\end{array}$ \\
\hline 13. & $\begin{array}{l}\text { Mapalipma INSITUT PER- } \\
\text { TANIAN MALANG }\end{array}$ & $\begin{array}{l}\text { Telah aktif sejak tahun } 1995 \text { dengan sejumlah kegiatan ekspedisi } \\
\text { ke seantero Nusantara dengan tujuan ekspedisi dalam rangka in- } \\
\text { vetarisasi flora dan fauna, pendakian, serta gerakan lingkungan } \\
\text { lainnya. }\end{array}$ \\
\hline \multicolumn{3}{|c|}{ Sumber: Peneliti 2019} \\
\hline
\end{tabular}

Wacana Kosmologis Romantisme Gunung

a. Konstruksi Identitas Pemuda Pecinta Alam

Seorang pemuda sengaja duduk di bangku belakang ruang kelas di kampus. Ia datang terlambat. Pagi itu ia masuk ke kelas dengan tas gunung lengkap dengan bordiran emblem serta ornamen-ornamen pendakian. Penampilannya tampak acak-acakan dibandingkan mahasiswa lainnya. Santai, seperti hendak mendaki ke gunung. Sontak semua teman kelasnya menyoraki “dasar anak gunung!". Itulah mereka, para 118 pendaki Pecinta Alam.

Apakah menjadi anggota Pecinta Alam harus menjadi pribadi yang terkesan memiliki 'template' yang serupa. Apabila diletakkan dalam konteks mahasiswa di universitas pada umumnya, seakan-akan pemuda pecinta alam ini sedang berupaya mengkonstruksikan identitas yang seragam dengan simbol-simbol yang sangat melekat pada komunitas mereka seperti penggunaan peralatan gunung dalam kehidupan sehari-sehari. Obrolannya bukan menyoal sim- 
bol-simbol yang dikonsumsi pemuda lainnya, melainkan label-label peralatan pendakian gunung yang bisa jadi harganya lebih mahal. Beberapa produk yang sering mereka gunakan seperti tas gunung, sendal gunung, botol minuman gunung, topi, celana, dan fashion lainnya lengkap dengan emblem-emblem terbordir menunjukkan jejak-jejak pendakian yang telah mereka lakukan. Beberapa juga menggunakan syal khas NTB-NTT yang disematkan diujung tali tas sebagai penanda, entah mereka pernah ke sana atau hanya oleh-oleh dari kawan.

"Nah, kalau yang diikat di tas itu dari Lombok, jadi khas para pendaki lah kalau di gunung buat ikat kepala, terus punya simbol-simbol. Ini pasti anak pecinta alam, banyak sticker atau gantungan kunci simbol udah pernah naik" (Rama, Informan)"

Kosmologis yang sedang dibangun oleh para pemuda Pecinta Alam ini adalah 'kosmologis pendakian gunung'. Tak mengenal tempat dan waktu, mereka terus berupaya mengonstruksikan simbol-simbol pendakian guna mengukuhkan diri sebagai seorang pendaki gunung. Roepstorff dkk (2003) mendefinisikan kosmologis sebagai praktik yang berkaitan dengan daya imajinatif dan reflektif manusia dalam mengonstuksikan atau membingkai sebuah realitas berdasarkan indera manusia. Dengan kesadarannya, manusia lantas mengimajinasikan relasi filosofisnya dengan alam dalam wadah imajinatif yang lantas dimaknai sebagai kosmologis. Kosmologis ini yang membuat anggota Pecinta Alam nampak begitu berbeda di kalangan pemuda lainnya jika dibandingkan dengan konteks kampus. Mereka terkesan tidak memperdulikan penampilan dengan gaya yang sering dicap "wah ini anak pecinta alam banget, kucel, gondrong, jarang mandi".

"Mungkin kita begitu, kaya seragam ya kumel dan cuek penampilannya karena sering bertemu dengan pendaki lain dan jadinya ya terpengaruh (Eki, Informan)"

"Mendaki itu bukan soal lomba-lomba seperti kegiatan di Pecinta Alam lainnya saat arung jeram yang menonjolkan sisi kehebatan antar-komunitasnya. Karena tidak ada perlombaan ini justru relasi sosial ketika di atas gunung yang menyebabkan kita saling kenal mengenal antar komunitas yang didominasi pemuda" (Rama, Informan).

Berdasarkan observasi yang dilakukan baik saat wawancara atau kegiatan-kegiatan pecinta alam di Malang, komunitas ini secara implisit telah membentuk identitas komunal berdasarkan orientasi yang sama pada hobi mereka kepada alam. Parsons (1977) membaca hal demikian dengan teori aksi yang menempatkan perilaku atau tindakan kolektif (collective orientation) seringkali berdasarkan pola-pola yang serupa pada objek yang mereka pertukarkan sebagai suatu simbol. Uniknya, simbol tersebut dipertukarkan dengan cara tindakan mobilitas dengan jejaring komunitasnya yang dapat terbentuk baik selama pendakian maupun setelah pendakian berlangsung.

Namun, tidak semua anggota Pecinta Alam merasa bahwa harus terus selaras dengan komunitasnya. Menurut mereka, mendaki gunung adalah sebuah hobi yang dapat dilakukan tanpa harus berkelompok. Alasan utama kenapa komunitas penting adalah memudahkan ketika pendakian berlangsung untuk membagi-bagi logistik, serta teman cerita. Namun tekanan utamanya adalah ada pula yang merasa bahwa stigma pecinta alam yang nampak sama seperti label masyarakat kepada mereka tidak sepenuhnya benar, karena itu semua tergantung dari diri sendiri.

\footnotetext{
"Ya, saya memang anggota (pecinta alam-ed), tapi secara pribadi saya menyatakan bukan bagian dari kawanan yang kaku itu. Kelompok mendaki, (bisa fleksibel -ed), itu aja sih (Raka, Informan)".
}

Dalam kacamata psiko-analisis yang dikemukakan oleh Arne Naess (1989) dengan kerangka konseptual ecosophy, konstruksi identitas individu maupun identitas kelompok yang berkaitan dengan sebuah gerakan lingkungan berbasis filosofis atau deep ecology movement selalu bertumpu pada koneksi manusia kepada alam (naturens egenverdi). Identitas kelompok 
para pendaki di Indonesia memang terkesan memiliki identitas komunal yang serupa, tetapi dibalik itu tetap individu adalah jiwa yang bebas dalam menarasikan identitasnya tanpa sepenuhnya tercampur oleh pengaruh komunitas. Bagaimana individu mendefinisikan sendiri identitasnya dalam kaitannya dengan alam disebut Selv-realisering pada kerangka ecosophy. Hal ini juga diamini oleh para peneliti leisure studies yang sama-sama memiliki judul artikel dengan topik 'walking and society'bahwa identitas yang sedang dibangun oleh para pendaki selalu berdasarkan pada refelksi diri (self-reflection) dan self-development karena kegiatan pendakian dapat dikategorikan sebagai meditasi berjalan yang mengedepankan komunikasi internal individu dengan dirinya sendiri untuk mengenali dirinya sendiri (Robinson 1989; Edensor 2000).

\section{b. Spiritualisme Pendaki Gunung}

Selain lewat penampilan rupanya para pemuda pendaki gunung ini mengaku memiliki unsur-unsur spiritual tersendiri yang menurut mereka menjadi pembeda dengan pemuda lainnya yang bukan pendaki gunung. "Gunung adalah bagian dari perjalanan hidup mereka”. Menemukan siapa diri mereka melalui pendakian dengan cara melepaskan diri dari jeratan-jeratan peradaban perkotaan yang menurut sebagian pendaki terlalu bising dan membuat hidup mereka tidak nyaman serta penuh tekanan.

"Bagi saya orientasi mendaki gunung itu adalah menikmati 'ketidakadaan peradaban dan keterikatan sosial. Jadi ya paling kita akan mengobrol tentang seputar perjalanan dan pengalaman. Mau makan jam berapa, logistik lah, serta bebas dari beban di kota. Ketika kita tidak bisa main Handphone yang ada hanyalah tentang diri kita dan sekitar kita, itu bebas dan lepas" (Raka, Informan).

Apa yang diungkapkan Raka diamini oleh sebagian besar pemuda pendakian yang diwawancarai dalam studi ini atau baik melalui dokumen-dokumen cerita blogspot di laman internet. Banyak di antara mereka mengatakan bahwa pendakian adalah suatu bentuk manifestasi "pelarian diri" dari bisingnya peradaban di perkotaan. Sehingga pendakian dapat diasumsikan seperti meditasi bagi mereka yang memahaminya sebagai ranah spiritualisme. Dalam diskusi yang lebih lanjut, Raka, informan dalam studi ini menuturukan bahwa sejak pertama kali ia mendaki gunung, ia seakan menemukan esensi kehidupan dalam perspektif lain, "seperti menjauh dari struktur sosial”, karena di gunung menurutnya adalah "tanah egaliter" di mana seorang pendaki tidak akan melihat pendaki lain dengan identitasnya di kota. Semua nampak sama di mata pendaki yang lain tanpa label-label identitas mereka ketika di kota. Oleh karena itu, menurutnya pendakian gunung mengajarkan kesetaraan yang dijunjung tinggi.

Kegiatan pendakian yang memiliki nilai spiritualisme yang tinggi dapat dikategorikan sebagai secular pilgrimage atau ziarah sekuler dalam studi-studi ziarah dan spiritual (MacCannel 1999). Ziarah sekuler melekat pada bagaimana komunitas pemuda pecinta alam juga turut mewacanakan aspek-aspek spiritualisme dalam kegiatan mereka di alam. Dalam hal ini, spiritualisme memang menjadi alasan utama individu dalam melakukan kegiatan berjalan kaki (walking) dan pendakian (hiking) pada tempat-tempat yang disakralkan (Eade dan Sallnow 1991; Coleman dan Elsner 1995). Perbedaannya dengan ziarah, kegiatan pendakian tidak selalu mendatangi gunung-gunung yang sakral semata, tetapi lebih kepada tindakan mengeksplorasi alam yang masih asri. Konteks spiritualisme dibangun berdasarkan wacana filosofis kedekatan manusia dengan alamnya. Sehingga menurut para anggota pendaki, pendakian hampir mirip dengan meditasi atau tindakan beribadah manusia kepada Tuhan. Ini juga tercermin misalnya lewat observasi yang dilakukan baik kepada komunitas maupun secara reflektif kepada pengalaman peneliti di mana memperlihatkan banyak larangan-larangan yang diyakini para pendaki harus dijalani saat pendakian seperti 'tidak boleh bicara kotor atau memiliki niat jahat' ketika pendakian karena gunung adalah 'rumah bagi mahluk-mahluk 
gaib'. Spiritualisme dalam konteks ini juga memperlihatkan bahwa para pendaki mempercayai mahluk lain di luar manusia hidup di alam bebas.

Lebih lanjut, pendakian dimaknai seperti halnya 'meditasi' mengenali dirinya sendiri. Mereka berusaha untuk lebih mencintai alam dengan tidak berbicara bahasa-bahasa kotor yang mereka percayai akan menimbulkan malapetaka karena gunung adalah tempatnya energi gaib yang harus dihormati. Selama pendakian, bukan hanya soal kepuasan dalam mencari ketenangan. Para pendaki juga mengaku lebih dekat dengan Tuhan dengan alamnya.

"Bagiku, mencintai alam adalah cara kita 'berterimakasih kepada bumi 'yang telah menyediakan apa pun yang kita butuhkan untuk keberlangsungan hidup kita. Mendaki adalah salah satu upaya mengenali alam itu sendiri agar kita tetap menjaga dan jangan merusak apa yang telah Tuhan berikan. Selalu ada rasa kagum terhadap pencipta saat mendaki lagi dan lagi” (Yogi, infoman).

Apa yang diungkapkan Yogi, mahasiswa perantauan dari Makassar di kota Malang, tentang upaya mensyukuri karunia Tuhan yang telah berikan lewat alam adalah suatu wujud kenapa komunitas pendaki gunung ini dinamakan pecinta alam. Ia menceritakan tentang kisah pengalamannya ketika kecil dulu saat di usia 9-10 tahun masih sempat melihat kunang-kunang dan capung, tapi karena alam sudah sedemikian rusak, sehingga mereka susah ditemui. Nostalgia masa kecil inilah yang kemudian dilanjutkan sebagai pecinta alam dengan mendaki ke puncak gunung sebagai wujud rasa cinta pada alam. Dengan mencintai alam, mereka akan mencintai seluruh yang Tuhan berikan ke alam ini yang bermuara pada rasa syukur serta ketenangan diri. Oleh karena itu, sangat wajar jika hal spiritualisme para pecinta alam akan bermuara pada “proses pencarian diri”.

"Mendaki adalah upaya mencari tahu siapa diri saya ini, mengendalikan ego saat pendakian bersama tim” (Mia, Informan).

Dalam konteks 'pencarian diri' yang terlekat da- lam kegiatan pendakian adalah salah satu upaya individu membangun kesadaran diri sebagai upaya mengonstruksikan identitas individu. Hal ini oleh George H Mead dikatakan sebagai the social construction of the self(MacCannell 1992). Dalam kaitannya dengan identitas komunal yang dibangun oleh komunitas pemuda pecinta alam berkaitan pula dengan konstruksi sosial terhadap dirinya dengan alam atau lagi-lagi terkait dengan ecosophy seperti yang telah dijelaskan pada bab sebelumnya.

Makna Gunung: Ecosophy dan Gerakan Lingkungan bagi Pecinta Alam

Di kalangan komunitas pemuda pecinta alam di Malang setidaknya terdapat 3 gunung paling favorit. Pertama, Gunung Semeru mendapatkan predikat paling favorit sepanjang masa bukan hanya oleh para Pecinta Alam di Malang, tetapi juga seluruh Indonesia. Di samping daya tariknya terhadap puncak tertinggi 3676 mdpl di pulau Jawa, Gunung Semeru juga memiliki danau Ranu Kumbolo yang disebut-sebut menjadi surganya Semeru. Bagi para pendaki gunung, mereka sudah memahami bahwa Gunung Semeru adalah salah satu gunung paling suci bagi umat Hindhu di Jawa atau Nusantara lainnya. Sejak abad ke-15 di akhir peradaban Majapahit, Puncak Mahameru diyakini sebagai puncak bersemayamnya para dewa tertinggi umat Hindhu. Kata Semeru sendiri diambil dari bahasa sangsekerta yaitu "Meru Agung" yang artinya pusat dari alam semesta baik secara fisik maupun spiritual. Hingga saat ini kosmologis gunung ini masih dijaga lewat eksistensi masyarakat Hindhu Tengger di sekitar gunung Semeru.

\footnotetext{
"Hmm gunung yang saya daki baru 4 sih, sejak jaman SMP dulu ke Gunung Galunggung terus ke Gunung Papandayan, terus kalau di Malang ya ke Gunung Arjuno dan Gunung Panderman, itu aja saya mah pemula, (Raka, Informan)".
}

Kedua, Gunung Panderman yang juga menjadi gunung favorit para pecinta alam di Malang. Hal ini nampak dari data sebelumnya yang menunjukkan sejumlah organisasi pecinta 
alam lahir di puncak Gunung Panderman. Jika diberikan alasan rasional, kenapa gunung ini menjadi gunung favorit bagi para Pecinta Alam di Malang dikarenakan gunung ini termasuk gunung yang aman bagi pemula yang tidak terlalu tinggi yang dapat ditempuh dengan pendakian selama 2 hari semalam. Ketiga, Gunung Arjuno yang memiliki ketinggian 3339 mdpl. Bagi para pendaki Pecinta Alam di Malang gunung ini tergolong sebagai gunung yang cukup sulit ditaklukan sehingga hanya para pendaki senior yang memilih menaklukannya karena predikat gunung paling curam dan berbahaya dibandingkan lainnya.

Jika dihubungkan antara pendakian gunung dan gerakan lingkungan dalam perspektif para pecinta alam maka hulu dari semua itu adalah 'ecosophy' atau kedalaman pemahaman diri akan betapa pentingnya menjaga alam dengan cara mencintainya. Gerakan lingkungan yang dimaksud akan bermula dari level individu dahulu yakni sisi jiwa para pendaki gunung tersebut. Menurut mereka seorang pendaki sejati adalah mereka yang naik gunung tanpa apapun dan turun tanpa apapun, atau dapat diartikan tidak merusak gunung.

\begin{abstract}
"Menurut para pendaki, yang mencintai alam itu adalah mountain man, yang pergi tanpa apapun dan turun tanpa apapun, menurut saya itu adalah sejatinya para pendaki. Pertama sebuah komitmen bahwa tidak ada satu bungkus pun yang mereka buang, sehingga pergi tidak membawa apa-apa, dan turun tidak membawa apa-apa. Inilah yang disebut sebagai gerakan individu mencintai alam. Satu prinsip yang menawarkan kedalaman jika tertular antara lingkungan pendaki itu sendiri”. (Raka, Informan).
\end{abstract}

Level ecosophy selanjutnya adalah tentang pemaknaan pendakian sebagai upaya pengendalian diri melalui tiga level. Menurut informan, Rohmat, "pendakian itu akan mendapat tiga olah yakni 'olah raga, olah rasa, dan olah pikir'. Selain jasmani yang akan bertambah sehat, seorang pendaki juga akan mendapat pengalaman yang banyak serta rasa (cinta -ed) ter- hadap kawan maupun alam”. Itulah kenapa naik gunung bukanlah hanya sekadar hobi semata melihat keindahan alam, tetapi juga tentang penempaan diri sendiri.

Selain pada level individu, gerakan yang bersifat advokasi juga dilakukan oleh para pendaki secara kolektif lewat diskusi-diskusi 'api unggun' saat bermalam bersama menghabiskan dingin malam dengan cerita-cerita bersama kawanan baru. Dari jejaring yang dibangun lewat perkenalan spontan para pendaki ini gerakan konkret yang pertama kali dilakukan oleh mereka adalah 'tindakan kolektif memunguti sampah' ketika pulang dari pendakian gunung.

Pada konteks Gunung Semeru, pasca banyaknya pemula yang latah untuk naik gunung akibat film 5 CM menyebabkan Mahameru sempat kelebihan kapasitas sehingga sampah para pendaki ini menumpuk. Mereka-mereka yang sadar prinsip dasar pendakian yakni 'pergi tidak membawa apa-apa, demikan juga pulang', menjadi diubah bahwa pulang belum tentu tidak membawa apa-apa, karena mereka bisa membawa pulang sampah gunung yang berserakan turun dari gunung. Tindakan spontan para pendaki ini dapat dikatakan sebagai gerakan lingkungan yang dilakukan secara kolektif tanpa harus perencanaan yang matang.

\begin{abstract}
"Kalau bicara lingkungan, ya mulai dari diri serta kelompok untuk menjadi pendaki yang sejati contohnya membawa sampahmu kembali turun saat setelah selesai mendaki, apalagi sampah plastik yang akan terurai setelah ratusan tahun. Tindakan kecil ini jika dicontoh oleh banyak orang dan kelompok, tentu akan bermanfaat bagi lingkungan itu sendiri maka dari itu ada jargon 'bawalah sampahmu turun, kalau perlu bawalah sampah orang di sekitarmu', biarkan orang dapat terpengaruh oleh tindakan kecilmu terhadap lingkungan (Raihan, Informan).
\end{abstract}

Selain itu, bagi para pendaki yang memang hendak belajar soal flora dan fauna yang ada di gunung, pendakian adalah media paling efektif untuk belajar tentang alam secara langsung. Dari pembelajaran ini akan muncul ide-ide gerakan 
konservasi yang lebih konkret karena setiap gunung tentunya memiliki lanskap yang berbeda-beda.

"Kita lebih tahu mengasihi lingkungan sih, lebih mengenal alam karena naik gunung itu penuh dengan tata krama, di sana kita tidak berusaha merusak alam dengan membawa pulang tumbuhan atau menangkap hewan. Di sinilah cara kita menghargai alam" (Syaiqul, Informan).

Seperti yang diungkapkan Syaiqul, informan lain bernama Hasan menambahkan bahwa kelestarian alam sangat berkaitan dengan ada atau tidaknya bencana di masyarakat perkotaan. Hutan adalah penyangga dari kehidupan umat manusia di bumi, "pohon hilang, bencana pun akan datang”. Hanya mereka yang gemar mendaki yang akan paham tentang perubahan iklim serta pencemaran lingkungan yang akan berdampak sangat buruk kepada hutan itu sendiri. Alam bisa saja murka karena perilaku kita, itulah kenapa manusia seharusnya juga mengasihi alam itu dengan cara konservasi dan tidak terus merambahnya.

"Jangan logika etnosentris itu dibawa ke mana-mana, karena kita ini yang butuh alam, sedangkan alam gak butuh kita, alam bisa saja mendepak kita jika dia murka”, (Syaiqul, Informan).

Makna Nasionalisme dan Gunung bagi Pecinta Alam

"Yang menarik, selalu ada bendera Indonesia di puncak gunung. Menurut saya itu hanya simbol nasionalisme, lebih dari itu para pendaki jelas sadar dengan negaranya sendiri selama pendakian mereka semakin sadar bahwa bangsa ini memiliki sumber daya alam yang sangat kaya, dari sini rasa nasionalisme semakin menguat" (Raka, informan).

Bukan hal yang mengejutkan memang ketika di seluruh puncak negeri selalu ada bendera Indonesia sebagai simbol nasionalisme para pendaki gunung yang telah menaklukan gunung hingga sampai ke puncak gunung. Unik memang, para pendaki selalu berusaha mengkaitkan antara kegiatan pendakian mereka sebagai wujud manifestasi rasa cinta mereka kepada bangsa dan negara Indonesia.

"Mendaki itu ibaratnya kita berjuang, seperti perjuangan dari para pahlawan dulu merebut kemerdekaan" (Rama, Informan).

Narasi-narasi heroik serta cerita-cerita soal negeri adalah obrolan sehari-hari para pecinta alam yang nampak lebih abstrak. "Anak Pecinta Alam itu obrolannya berat-berat”, banyak yang mengatakan demikian. Tidak ada salahnya juga, bagi para pecinta alam, pendakian memang lebih banyak diisi dengan diskusi-diskusi soal narasi kehidupan dan perjuangan ketimbang persoalan percintaan yang sering menjadi topik paling sering dibicarakan di kalangan anak muda itu sendiri. Lalu apa relevansinya antara nasionalisme dengan pendakian gunung?

“Tak kenal maka tak sayang, jangan sampai kaya orang luar (mancanegara-ed) yang lebih kenal alam negeri kita, daripada kita sendiri. Ini representasi rasa nasionalisme kita dengan mengibarkan bendera kebanggaan kita di puncak tertinggi sebagai gambaran perjuangan kita pada bangsa ini” (Rohmat, Informan).

Nasionalisme bagi para pendaki adalah ruh dalam diri yang secara tidak langsung telah melekat ke dalam kegiatan mereka yang berusaha mengenali lebih dalam alam sekitarnya. Itulah mengapa banyak yang berusaha 'merayakan' nasionalisme ini dengan mengikuti upacara 17 Agustus sebagai bentuk rasa syukur mereka telah lahir dan besar sebagai bangsa Indonesia.

"Nasionalisme itu perjuangan, seperti kita mendaki gunung itu ya perjuangan. Rasa heroik dalam diri ini secara spontan di puncak gunung kita akan melakukan selebrasi dengan pengibaran bendera mera putih. Ada rasa haru yang tidak terkira ketika kita sudah mencapai puncak. Apalagi jika di Semeru, pas 17 Agustus pasti akan banyak sekali para pendaki yang ingin mengalami upacara bendera ketika di puncak gunung, di situ rasa haru begitu kuat seperti perjuangan kita mendaki puncak gunung. Jadi kita bisa mengaitkan itu" (Rama, Informan). 
Menurut para pendaki, upacara bendera 17 Agustus yang dilakukan di puncak gunung adalah manifestasi mereka mencintai negerinya yang maha kaya. Mendaki puncak gunung adalah sebuah kebanggaan bagi para pemuda sehingga memunculkan rasa heroik tersendiri di antara mereka. Sehingga sangat wajar bagi mereka rasa heroik tersebut dikonstruksikan lewat simbol-simbol nasionalisme seperti bendera Indonesia. Walaupun misalnya para pendaki ini tidak berkesempatan melakukan pendakian pada hari ulang tahun kemerdekaan Indonesia, ketika di puncak gunung, hampir semuanya pasti akan menyanyikan lagu Indonesia Raya sebagai wujud rasa patriotik diri seorang pendaki gunung yang telah menaklukan dirinya sendiri hingga sampai ke puncak gunung.

Studi ini selaras dengan studi yang dilakukan oleh Ween dan Simone (2012) pada kalangan pendaki Norwegia. Mereka menyebut nasionalisme yang dibangun oleh kalangan para pendaki Norwegia tersebut dengan 'Nature-Nationalism”. Meminjam idiom nasionalisme yang dibangun oleh Benedict Aderson, dalam kaitannya dengan alam hal ini berkaitan erat dengan sense of belonging atau rasa memiliki komunitas pendaki terhadap lanskap alam negerinya. Melalui imajinasi patriotik, kegiatan pendakian dimaknai sebagai upaya membangun kesadaran individu pada rasa cinta tanah air yang mendalam dan tertanam pada bangunan filosofis identitas individu seseorang. Janowitz (1985) memberikan hipotesisnya untuk merekonstruksikan kembali patriotisme sebagai sesuatu hal yang sangat cair dan tidak hanya terlekat pada ideologi politik dalam berbangsa dan bernegara. Lebih dari itu nilai-nilai patriotisme juga dibangun lewat kegiatan-kegiatan komunal yang diinisiasi oleh komunitas yang mengatasnamakan suatu bangsa. Inilah yang disebut sebagai 'civic consciousness' atau rasa keterikatan individu terhadap bangsa negaranya. Alih-alih mengunakan terminologi nasionalisme, Amato (2004) menyebut rasa cinta tanah air yang muncul dalam kegiatan pendakian ini sebagai 'landscape patrio- tism'di mana nilainya lebih kuat dan mendalam dibandingkan hegemoni patriotisme dalam konteks negara. Dalam konteks studi ini, ritus-ritus yang dilakukan oleh komunitas pemuda pecinta alam adalah upaya komunal para pendaki untuk membangun apa yang disebut sebagai landscape patriotism dengan serangkaian gerakan-gerakan berbasis lingkungan yang diwacanakan oleh mayoritas komunitas pecinta alam di seluruh Indonesia, khususnya di Malang.

\section{KESIMPULAN}

Wacana tentang ecosophy dan nasionalisme, yang tercermin dalam studi ini, memiliki benang merah yang serupa yakni berupa nilainilai intrinsik yang diartikan secara filosofis oleh setiap individu. Seperti halnya ecosophy yang melekat sebagai suatu nilai yang 'harus dicari' lewat pencarian diri sendiri dengan pendakian hingga ke puncak gunung. Bagi para komunitas pemuda Pecinta Alam, nasionalisme adalah sebuah nilai yang juga harus dicari dan diperjuangkan. Keduanya bukanlah suatu sistem nilai budaya yang diwariskan begitu saja. Pemaknaan yang dangkal menyebabkan keduanya tidak terlampau berarti. Bagi para pemuda yang tergabung dalam pecinta alam, salah satu cara menemukan nilai-nilai ecosophy adalah dengan mengasingkan diri dari peradaban perkotaan lewat tinggal bersama komunitasnya di atas gunung dengan alam yang asri. Perjalanan ke puncak gunung adalah 'selv-realisering' seperti yang diungkapkan Naess sebagai 'active condition' menemukan dirinya sendiri agar terkoneksi dengan alam. Narasi-narasi dari informan di atas jelas menunjukkan bahwa mayoritas motif para pemuda menggeluti pendakian selain karena mencintai alam, juga sebagai proses menemukan dirinya sendiri lewat penaklukan ego-ego dalam dirinya agar lebih dekat dengan komunitas dan alamnya. Selaras dengan namanya, pecinta alam jelas adalah suatu komunitas yang menurut Naess disebut sebagai proses identifikasi menuju naturens egenverdi atau koneksi individu dengan alamnya. Walaupun belum memiliki dampak secara masif jika dibandingkan dengan 
NGO lingkungan yang berafiliasi pada pemerintah atau donor lembaga internasional, Pecinta Alam dapat dikategorikan pula sebagai 'deep ecology movement' karena yang ditekankan adalah kedalaman anggotanya memaknai untuk lebih dekat dengan alam secara filosofis. Gerakan lingkungan yang mendalam inilah yang kemudian membentuk 'imagined community' ketika pendakian dilakukan di atas gunung. Kebanyakan dari para pendaki tidak saling mengenal tetapi memiliki perasaan yang serupa terhadap kelestarian alam dan rasa solidaritas yang tinggi untuk dapat saling membantu mencapai puncak. Selebrasi berwujud upacara bendera, khususnya saat 17 Agustus di puncak gunung adalah representasi dari rasa kepemilikan bersama para pendaki pada tanah airnya yang diwujudkan secara patriotik lewat simbol bendera merah putih. Dapat dikatakan koneksi antara ecosophy dan nasionalisme terepresentasi lewat romantisme pendakian hingga puncak gunung.

\section{DAFTAR PUSTAKA}

Amato, J. 2004. On Foot: A History of Walking: New York: New York University Press.

Anderson, Benedict. 1983. Imagined Communities: Reflection on the Origin and Spread of $\mathrm{Na}^{-}$ tionalism. London and New York: Verso.

Arifin, Zainal. 2018. "Tiga lokasi Upacara 17 Agustus di Gunung Semeru'. Liputan6. Diakses melalui website pada 14 Juli 2019, https://www.liputan6.com/regional/ $\mathrm{read} / 3620934 /$ tiga-lokasi-upacara-17-agustus-di-gunung-semeru

Coleman, S and J. Elsner. 1995. Pilgrimage Past and Present in the World Religions. Cambridge. Cambridge: Harvard University Press.

Eade, John and Sallnow. 1991. Contesting the Sacred: The Anthropology of Christian Pilgrimage. London: Routledge.

Eberle, Thomas S. 2015. "Exploring Another's Subjective Life-World: A Phenomenological Approach". Journal of Contemporary Ethnography Vol. 44(5) 563-579
Edensor, T. 2000. "Walking in the British Countryside: Reflexivity Embodied practices and ways to escape". Body and Society 6, pp. 81106.

Finlay, Linda. 1999. "Applying Phenomenology in Research: Problems, Principles and Practices". British Journal of Occupational Therapy 62(7).

Forbes, Hamish. 2007. Meaning and Identity in a Greek Landscape. An Archaeological Ethnography. Cambridge: Cambridge University Press.

Hartik, Andi. 2018. "Pendaki Dilarang Gelar Upacara Kemerdekaan di Puncak Mahameru”. Kompas.com. Diakses melalui website pada 14 Juli 2019 https://malang.kompas.com/ $\mathrm{read} / 2018 / 08 / 15 / 13210371 /$ pendaki-dilarang-gelar-upacara-kemerdekaan-di-puncak-mahameru.

Janowitz, M. 1985. The Reconstruction of Patriotism. Chicago, IL: The University of Chicago Press.

Katriel, T. 1995. "Touring the Land: Trips and Hiking as Secular Pilgrimage in Israel Culture". Folklore and Ethnology Review 1, pp.6-13.

Kellerman, A. 2012. Daily Spatial Mobilities Physical and Virtual. Farnham: Ashgate.

Knoblauch, Hubert. 2005. "Focused Ethnography [30 Paragraphs].” Forum Qualitative Sozialforschung / Forum: Qualitative Social Research 6 (3): Art. 44.

Kreiner, Collins Noga and Nurit Kliot. 2017. "Why Do People Hike? Hiking the Israel National Trail". Tijdschrift voor economische en sociale geografie (Journal of Economic and Social Geography). Vol. 108, p 669-687.

Lehn, vom Dirk and Hitzler, Ronald. 2015. "Phenomenology-Based Ethnography: Introduction to the Special Issue". Journal of Contemporary Ethnography, Vol. 44 (5), p 539-543.

MacCannell, Dean. 1992. Empty Meeting Grounds: The Tourist Papers. London: Routledge.

MacCannell, Dean. 1999. The Tourist : A New Theory of the Leisure Class. Los Angeles: 
University of California Press.

Marcus, G. 1995. "Ethnography in/of the world system: The emergence of multi-sited ethnography". Annual Review of Anthropology, 24 (1): $95-117$.

Naess, Arne. 1989. Ecology, Community and Lifestyle: Outline of an Ecosophy. Cambridge: Cambridge University Press.

Parsons, T. 1977. Social Systems and the Evolution of Action Theory. New York: The Free Press.

Pink, S., and J. Morgan. 2013. "Short-Term Ethnography: Intense Routes to Knowing." Symbolic Interaction 36 (3), 351-61.

Robinson, J.C. 1989. The Walk: Notes on a Romantic Image. London: Dalkey Archive Press.

Roepstorff, Andreas, dkk. 2003. Imagining Nature: Practices of Cosmology and Identity. Aarhus Denmark: Aarhus University Press.

Solnit, R. 2000. Wanderlust: A History of Walking: New York: Viking.

Suharko, dkk. 2014. Organisasi Pemuda Lingkungan di Indonesia Pasca Orde Baru. Yogyakarta: Gadjah Mada University Press.

Urry, J. 2007. Mobilities. Cambridge: Polity.

Ween, Gro and Abram Simone. 2012. "The Norwegian Trekking Association: Trekking as Constituting the Nation." Landscape Research, 37:2, 155-171

Wojnar, D. M. and Swanson, K. M. 2007. "Phenomenology: An Exploration”. Journal of Holistic Nursing Volume 25 Number 3, 172-180.

Yustiana, Kurnia. 2018. "Upacara 17 Agustus di Puncak Semeru Dilarang!”. Detiktravel. Diakses melalui website pada 14 Juli 2019. (https://travel.detik.com/travel-news/d-4109474/upacara-17-agustus-di-puncak-semeru-dilarang) 